\title{
How Much Do We Care About Absolute Versus Relative Income and Consumption?
}

\author{
Francisco Alpizar \\ Fredrik Carlsson \\ Olof Johansson-Stenman ${ }^{\mathbf{A}}$ \\ Working Papers in Economics no. 63 \\ November 2001 \\ Department of Economics \\ Göteborg University
}

\begin{abstract}
We find, using survey-experimental methods, that most individuals are concerned with both relative income and relative consumption of particular goods. The degree of concern varies in the expected direction depending on the properties of the good. However, contrary to what has been suggested in the previous literature, we find that relative consumption is also important for vacation and insurance, which are typically seen as non-positional goods. Further, absolute consumption is also found to be important for cars and housing, which are widely regarded as highly positional. Implications for Pareto-efficient taxation are illustrated using the results from the experiment.
\end{abstract}

Keywords: status, relative income, optimal taxes, experiments

JEL-classification: C91, D63, H21

We are grateful for valuable comments from seminar participants at Göteborg University and Resources for the Future (RFF). Financial support from the Swedish Transport and Communications Research Board (KFB), the Swedish International Development Agency (SIDA) and the Bank of Sweden Tercentenary Foundation is gratefully acknowledged.

A Department of Economics, Gothenburg University, Box 640, SE-405 30 Gothenburg, Sweden. E-mail: francisco.alpizar@economics.gu.se, fredrik.carlsson@economics.gu.se,olof.Johansson@economics.gu.se 


\section{Introduction}

There is considerable evidence that relative income and consumption are important determinants of both individual well-being and behavior, and even Adam Smith in his day noted that women in England required better clothing to appear in public without shame than women in Scotland did. Seminal contributions include Veblen (1899) who used the term conspicuous consumption to refer to expenditure in goods that signal the consumer's position in society, and Duesenberry's (1949) theory of consumption, which emphasized the importance of relative standings in determining consumption and savings patterns over time. Weiss and Fershtman (1998), Holländer (2001) and Brekke and Howarth (2002) provide good overviews of more recent literature on and implications of social status.

Still, the issue of how important relative income and consumption are for individual well-being, compared to their absolute counterparts, is much more difficult to answer, and this is the main concern of this paper. On one extreme, standard economic theory typically assumes, based on no empirical evidence, that only absolute income and consumption matter. On the other extreme, Easterlin (1974, 1995), Oswald (1998) and others conclude that only relative income seems to matter. This conclusion is largely based on a large number of survey-based psychological studies, where it is found that happiness increases with income in a given country and in a given year, but also that average happiness in a given country seems to be roughly constant over time, even though average income increases. Furthermore, people also seem to be about equally as happy in different countries with different incomes. These studies have been criticized, however, and Brekke (1997) and Osmani (1993) argue that people may respond to questions about happiness relative to a subjective happiness norm, and that this norm may be income-dependent too. A "very happy" response in a rich society would then reflect a happier person than the same response in a poorer society. Happiness would then still depend, at least partly, on absolute income. This clearly illustrates the need for alternative empirical methods.

An alternative strategy for measuring the importance of relative standing is to ask individuals hypothetical questions regarding their choice among alternatives states or outcomes, where their choice reveals their concern for relative positions (JohanssonStenman et al., 2002; Solnick and Hemenway, 1998). Johansson-Stenman et al. used an 
experiment where Swedish students made repeated choices between alternative societies, described by an imaginary grandchild's income and the average income. For example, in one society the grandchild's income was $\$ 2500 /$ month which was lower than the average income of $\$ 3000 /$ month. In the other society the grandchild's income was $\$ 2300$ which is higher than the average income of $\$ 2000 /$ month. The task was to decide in which society the grandchild would be most content. It was found that most people do care about relative income, but also that absolute income is in most cases important for individual well-being. Here we largely follow the same experimental design when measuring the positionality degree for income, although we apply it to a student sample from Costa-Rica.

However, if income contributes to utility solely instrumentally through consumption, as is typically assumed, then utility must depend on relative consumption. The literature on positional goods (Hirsch 1976, Frank 1985a, b) dealing with this issue, typically assumes that some goods are much more positional than others, so that relative consumption is more important for goods such as jewelry, cars and houses compared to more non-positional goods such as bread, insurance and leisure. If this is correct, important policy implications follow, as extensively discussed by Frank (1985a, b). For example, it can be socially optimal to have higher taxes on goods that are more positional, as demonstrated in Section 5 of this paper. Boskin and Sheshinski (1978) and Ireland (2001) show that the optimal amount of redistribution from income taxes increases when income is partly positional and leisure is purely non-positional, and Persson (1995) attempts to explain the very high income taxes in some countries, such as Sweden, using similar assumptions. Ljungqvist and Uhlig (2000) find arguments for a Keynesian stabilization tax policy, where it is again assumed that leisure is purely non-positional. $\mathrm{Ng}$ (1987) and $\mathrm{Ng}$ and Wang (1993) show that publicly provided goods, such as environmental quality, should be over-provided relative to the basic cost-benefit rule in the case where relative private consumption or income matters for utility, and where the publicly provided good is non-positional.

The empirical evidence for the hypothesis of varying degrees of positionality, besides introspection, is scarce, however. The only study, to our knowledge, that attempts to empirically investigate the positionality degree for different goods is Solnick and Hemenway (1998). They let American students choose between one "relative 
alternative" and one "absolute alternative" for each good. They found that the concern for relative standings was strongest for the students' own attractiveness and supervisor's praise, while weakest for vacation time. They also found that on average $48 \%$ of the respondents preferred the society with a higher relative but lower absolute income, which is perfectly consistent with the findings of Johansson-Stenman et al. (2002) if parameterized in the same way. However, since Solnick and Hemenway did not ask repeated questions for each good, they did not produce any parameter estimates of the positionality degree. This is therefore done here for the first time (as far as we know), by extending the experimental design from Johansson-Stenman et al. to different goods.

Section 2 describes the models underlying the experiments on the importance of relative income and consumption. Section 3 presents the set-ups and Section 4 the results of the experiments. Section 5 derives and calculates Pareto-efficient consumption taxes based on the obtained positionality estimates. Finally, Section 6 draws conclusions.

\section{Modeling Relative Consumption and Relative Income}

There are many ways to incorporate relative standing into the utility function. Most studies have either used some kind of ratio comparison utility function, $U=v(x, r) \equiv v(x, x / \bar{x})$, where $x$ is the individual's income (or consumption vector of different goods) and $\bar{x}$ is the average income in society (e.g. Duesenberry, 1949; Boskin and Sheshinski, 1978; Layard, 1980; Persson, 1995; Carroll et al., 1997), or some kind of additive comparison utility function, $U=v(x, r) \equiv v(x, x-\bar{x})$ (e.g. Akerlof, 1997; Corneo and Jeanne, 1997; Knell, 1999; Ljungqvist and Uhlig, 2000). Clark and Oswald (1998) show important theoretical differences between these formulations, but the empirical evidence is scarce. The only result we are aware of is Johansson-Stenman et al. (2002) who, in a simple test, compared the ratio comparison utility function

$$
v=x^{1-\gamma}\left(\frac{x}{\bar{x}}\right)^{\gamma}
$$

to the additive comparison utility function 


$$
v=x-\delta \bar{x}
$$

Although the ratio-formulation performed better in terms of explaining respondent behavior, they concluded that more research is clearly needed. Lacking clear empirical evidence, we will present the results for both of these functional forms. ${ }^{1}$

It is likely that the positional concern is more complex in reality than in the stylized models most often used. For example, Knell (1999) analyses theoretically "within-class comparison", "upward comparisons" and "society-wide comparisons". The first two cases include people who care for their status as members of a specific group, and those who want to be like the ones with higher status, respectively. Nevertheless, for empirical and experimental simplicity we solely deal with the latter type of comparison, i.e. we assume that people compare themselves to the average in society, which enables us to estimate the positionality degree for each good with only one parameter. It is easy to verify that the parameters $\gamma$ and $\delta$ in (1) and (2) measure the marginal degree of positionality,

$$
\alpha=\frac{\frac{\partial v}{\partial r} \frac{\partial r}{\partial x}}{\frac{\partial v}{\partial x}+\frac{\partial v}{\partial r} \frac{\partial r}{\partial x}}
$$

i.e. the fraction of the total utility change which comes from increases relative consumption from the last dollar spent. Still, in future research it would be of interest to consider less restrictive formulations.

\section{Measuring Positionality}

Consider a hypothetical choice between two societies, where in society A the individual's income is $\$ 2500$ per month and the average income is $\$ 3000$, while in society B the individual's income is $\$ 2040$ per month and the average income is $\$ 2000$.

\footnotetext{
1 Since we are only interested in the ordinal properties of the utility function, any monotonic transformation of (1) and (2) are equally valid utility functions.
} 
In all other respects, the societies are identical. If an individual is indifferent between these two societies, we have in the case of the ratio comparison utility function that

$$
\left(x_{A}\right)^{1-\gamma}\left(\frac{x_{A}}{\bar{x}_{A}}\right)^{\gamma}=\left(x_{B}\right)^{1-\gamma}\left(\frac{x_{B}}{\bar{x}_{B}}\right)^{\gamma} \rightarrow \gamma=\ln \left[\frac{x_{B}}{x_{A}}\right] / \ln \left[\frac{\bar{x}_{B}}{\bar{x}_{A}}\right]=0.5
$$

while for the additive comparison utility function we have that

$$
x_{A}-\delta \bar{x}_{A}=x_{B}-\delta \bar{x}_{B} \rightarrow \delta=\frac{x_{A}-x_{B}}{\bar{x}_{A}-\bar{x}_{B}}=0.46
$$

Hence, if an individual is indifferent between the two societies we have that $\gamma=0.5$ (or that $\delta=0.46$ ). Consequently, if he/she prefers society A then $\gamma<0.5$ (or $\delta<0.46$ ), and vice versa. By letting individuals make repeated pair-wise choices between hypothetical societies with different implicit marginal degrees of positionality, it is possible to more precisely estimate the degree of positionality for income.

We use similar experiments to measure the degree of positionality for different goods, by letting individuals make tradeoffs between their own consumption and their relative consumption, keeping everything else equal. In Appendix 1 it is shown that the marginal degree of positionality for income is equal to a weighted sum of the marginal positionality for each good, where the weights are the income shares spent on each good. This holds irrespective of the structure of relative consumption, e.g. whether ratio or additive comparisons, or a combination of these, is the correct formulation. This implies that if only relative income matters for happiness, then all market goods must have a value of $\alpha$ equal to one, given that $\alpha$ cannot be larger than one for any single good. Conversely, if $\alpha$ is not equal to one for all goods, it follows that absolute income as well must matter for utility. On the other hand, if $\alpha$ varies among the goods, i.e. is not equal to zero for all goods, it follows that utility must depend on both absolute and relative income. 


\section{Design of the Experiments}

A total of 325 students from The University of Costa Rica took part in the experiment. The students were interviewed in the classroom as part of a lecture, and the average group size was 30 students. ${ }^{2}$ The survey lasted for approximately 30 minutes, and there was no show-up fee paid. The respondents were given verbal information before each section of the experiment, in addition to printed information.

The experiment consisted of three sections: (i) the relative income experiment, (ii) the relative consumption experiment and (iii) questions regarding the respondent's socio-economic status. Following Johansson-Stenman et al. (2002), the respondents were instructed to consider the well-being of their imagined grandchild when making their choices. This was to help the respondents liberate themselves from their current circumstances. Further, it is possible that utility may also depend on income and consumption changes over time (i.e. positional in the time-dimension); see e.g. Frank and Hutchens (1993). They were frequently reminded that they should not choose what they considered the overall best society, but the society that would be the best for their grandchild. The students were told that the societies were identical in all respects, except the issue being analyzed. It was also stressed that prices and goods were the same in all societies.

Our main hypothesis is that the students will use their own preferences when responding, since they for obvious reasons have very limited information regarding their hypothetical grandchild's preferences. However, it is possible that some base their answers on their view of what matters for peoples' well being in general, i.e. on some kind of perceived average preferences, rather than on their own preferences.

\section{The Relative Income Experiment}

In the relative income experiment, the respondents make repeated choices between two societies, A and B, described by the average income and the grandchild's income. In all other respects, the societies are identical. Society A is a fixed alternative where the average income is 360,000 Colones/month and the grandchild's income is 300,000

\footnotetext{
2 This was a general course offered to students in several different areas including law, economics, engineering, political science, and natural sciences, among others.
} 
Colones/month. ${ }^{3}$ This society is then compared with seven different B societies with varying individual incomes but a given average income (an example is presented in Appendix 2). The grandchild's income in society B was chosen such that it corresponds to a certain degree of positionality if the individual is indifferent between the two societies. This is calculated both for the ratio comparison in (1) and for the additive comparison in (2). The societies are presented in Table 1, which also shows the order in which they were presented in the experiment.

>> Table 1.

If an individual chooses society $\mathrm{B}$ in questions 1 and 2, but society $\mathrm{A}$ in question 3 , then the individual is willing to sacrifice 15,000 Colones/month in order to be above the average, but not as much as 30,000 Colones/month. This corresponds to a marginal degree of positionality between 0.125 and 0.25 for both the additive comparison and the ratio comparison case.

\section{The Relative Consumption Experiment}

In the experiment on relative consumption, the respondents make choices between two societies described by the average consumption and the grandchild's consumption of a particular good. Again, the societies are identical in all other respects. To test the hypothesis that the degree of positionality depends on the type of good that is consumed, we include four different types of consumption in the experiment: cars, housing, insurances and days of vacation.

But how much to spend on each good is of course up to the consumer in a free society. Therefore it is not straightforward to generalize the relative income experiment to measure the importance of relative consumption of different goods. We deal with this problem by letting the company at which the grandchild works provide the goods as a fringe benefit. For example, the grandchild could receive a car at a value of 5,000 Colones per month as a benefit. The grandchild is then still free to choose characteristics such as size and brand according to his/her taste, as long as the value corresponds exactly to the one specified for that good. For each good the respondent

\footnotetext{
${ }^{3} 1$ US Dollar corresponds to 300 Colones using the exchange rate of November 2001.
} 
makes three choices between a fixed alternative A and a varying alternative B (an example is presented in Appendix 2). The construction is, in all other respects, the same as for the relative income experiment, and the choices will reveal the marginal degrees of positionality. The societies are presented in Table 2, along with the implied marginal degree of positionality if the respondent is indifferent between the two societies.

>> Table 2.

\section{Results of the Experiment}

\subsection{Income Experiment}

Of the 325 responses, $13.5 \%$ were inconsistent in the sense that they switch from choosing society A, to choosing society $\mathrm{B}$ in a later choice, which violates the monotonicity assumption of the utility function. Some potential explanations for such behavior are learning and fatigue effects. ${ }^{4}$ Irrespective of the cause, we exclude these responses from the analysis. The results of the experiment are presented in Table 3.

\section{>> Table 3 .}

The median degree of positionality is between 0.25 and 0.5 ( 0.25 and 0.45 for the additive comparison case). However, the distribution of responses is almost bipolar; $44 \%$ of the respondents have a degree of positionality of less than 0.1 , and $31 \%$ have a degree of positionality higher than 1.0. The mean degree of positionality is 0.45 and 0.40 , respectively. ${ }^{5}$

In Section 2 we defined the marginal degree of positionality as the fraction of the total utility change from the last dollar spent which comes from increased relative income or consumption. Our results show that, on average, $45 \%$ of the utility increase from a small income increase arises from enjoying a higher relative income (40\% for the additive formulation). This fraction is clearly lower than the hypothesis of $100 \%$

\footnotetext{
${ }^{4}$ Using a binary probit model, we tried to explain the occurrence of inconsistent responses, but none of the parameters were significant.

${ }^{5}$ The individual marginal degree of positionality is set to the median value of the corresponding interval. For the extreme cases $\gamma \leq 0$ and $\gamma \geq 1$ we set the degree to -0.0625 and 1.05 respectively, and for the extreme cases $\delta \leq 0$ and $\delta>0.83$ we set the degree to -0.0625 and 0.95 respectively. In our theoretical model, both $\delta$ and $\gamma$ are in the closed interval [0,1], but the construction of the experiment does not allow for indifference, therefore the adjustment described above.
} 
corresponding to the hypothesis that only relative income matters, but it is also higher than the $0 \%$ hypothesis stating that only absolute income matters.

\subsection{Consumption Experiments}

The results of the consumption experiments are presented in Table $4 .^{6}$

\section{>> Table 4.}

The median degree of positionality is between 0.5 and 0.75 (0.46 and 0.66$)$ for cars and housing, while lower than $0.25(0.24)$ for insurance and vacation. The same pattern holds for the mean degree of positionality. ${ }^{7}$ Consequently, there are differences in the degree of positionality in the expected direction among different types of goods; the more visible goods, cars and housing, are more positional than less visible ones. At the same time it is surprising that the mean degree of positionality is relatively high even for goods such as vacation and insurance. Solnick and Hemenway (1998) asked American students to choose between 1 week of vacation for themselves given that others had none, and 2 weeks given that others had 4 weeks on average; this implies that $\delta=0.25$ in the case of indifference. Only $20 \%$ went for the positional alternative, compared to about $50 \%$ in Table 4.

As expected, the mean degree of positionality for income is in between the corresponding values for the less positional goods, vacation and insurances, and the more positional goods, cars and housing (remember that marginal degree of positionality for income is a weighted sum of the marginal degrees of positionality for each good, as shown in Appendix 1).

\subsection{Hypothetical Bias and Identity}

There are several potential explanations for the large share of "extreme" answers, besides the fact that these might reflect true preferences. It appears reasonable that some respondents used a lexicographic strategy as a cognitively cheap attempt at solving the exercise, even though their underlying true preferences may be more complex (see e.g.

\footnotetext{
6 The share of inconsistent responses varied between $4 \%$ and $7 \%$ in the different consumption experiments. Again, we exclude these responses from the analysis.
} 
Payne et al. 1993). Another possibility is related to the desire to obtain a certain selfimage. Akerlof and Kranton (2000) argue that individuals' self-image, or identity, is an important factor in explaining many kinds of human behavior. If individuals wish a selfimage of either being concerned or not being concerned about status, lexicographic responses seem rational. Similarly, to understand a complex world we clearly need to simplify it, implying that more simplistic explanations are often attractive. Arguably, a world where individual well-being depends solely on absolute consumption, or solely on relative consumption, is easier to comprehend than a world where well-being depends on both absolute and relative consumption. Lexicographic responses are useful in maintaining or amplifying both of these views.

In Table 5, we therefore report the results of the experiments when removing two types of lexicographic responses: (i) respondents who always opted for society A, i.e. they are non-positional for all goods and (ii) respondents who always opted for society B, i.e. they are highly positional for all goods. After removing the lexicographic responses the positionality differences increase among the goods. We only report the result for the ratio-comparison utility function, but the pattern is the same for the difference-comparison case.

\section{>> Table 5 .}

\subsection{Econometric Analysis}

We now turn to the question of which individual factors determine the responses in terms of positionality. This is analyzed with an ordered probit for each of the experiments. For presentational ease we group the responses from the income experiment corresponding to the responses of the consumption experiments - the qualitative results are not affected by this grouping. Since the experiment is complex, we feared that there could be order effects and enumerator effects (there were three different enumerators). Therefore, the order of the goods was shifted in the second part of the experiment. However, after testing for order and enumerator effects in the

\footnotetext{
${ }^{7}$ The individual marginal degree of positionality is set to the median value of the corresponding interval. For the extreme cases $\gamma<0.25$ and $\gamma>0.75$ we set the degree to 0.05 and 0.95 respectively, and for the extreme cases $\delta<0.25$ and $\delta>0.66$ we set the degree to 0.05 and 0.86 respectively.
} 
ordered probit models we cannot reject the absence of such effects, except for the housing experiment where we could not reject an interview or an order effect.

Table 6 reports the estimated marginal effects for the income and the consumption experiments. ${ }^{8}$ A positive marginal effect for a given interval indicates that an increase in the explanatory variable increases the probability that an individual will have a marginal degree of positionality located in that interval.

\section{$>>$ Table 6}

The results from both the income and consumption experiments suggest that women care relatively more about status than men do. One could speculate that there might be decreasing returns to status, so that status is relatively more important for low-status individuals. In a society traditionally dominated by men, such as Costa Rica, a higher status might therefore be especially beneficial for women. It is also possible, however, that the female responses reflect a more socially oriented world-view, where comparisons to others are more important, rather than differences in preferences. The same arguments can be applied to left-wing voters (defined as those who would vote for either of the two parties PLN and PFD), who appear to care more about status in income and housing than others do. Indeed, there is a tradition in socialist writings to emphasize social comparisons, expressed here by Karl Marx (1891, Ch. 6):

A house may be large or small; as long as the neighbouring houses are likewise small, it satisfies all social requirements for a residence. But let there arise next to the little house a palace, and the little house shrinks to a hut. The little house now makes it clear that its inmate has no social position at all to maintain, or but a very insignificant one; and however high it may shoot up in the course of civilization, if the neighbouring palace rises in equal or even in greater measure, the occupant of the relatively little house will always find himself more uncomfortable, more dissatisfied, more cramped within his four walls.

We also find that the concern for status is decreasing in the parents' income (since most students do not have an income of their own, we asked for an estimate of their parents' income). For the income experiment, we obtain a positive and significant marginal

\footnotetext{
${ }^{8}$ The models were estimated using Limdep 7.1. For details on estimation and calculation of marginal effects, see Greene (2000).
} 
effect for the interval $\gamma<0.25$, and a negative and significant one for the interval $\gamma>0.75$. A similar pattern holds for the consumption experiments, although most marginal effects are insignificant. There are again many possible explanations. One could argue that the parents' income, in part, is endogenous with respect to the preferences, and that the likelihood of obtaining a high income decreases with the resources spent on status-seeking behavior, and that these preferences are carried over from parents to children. However, this argument could be reversed, since high status can also be a strong motivation for becoming rich. Indeed, Mandeville (1723) in The Fable of the Bees has already claimed that conspicuous consumption encouraged people to work harder. Another possibility is that high-income individuals care less about comparisons to the mean income in society; instead, they might be concerned with status in a richer subgroup.

It also turns out that the students' majors reveal large differences in concerns regarding status. Students majoring in economics, law and social sciences are more concerned about status than students majoring in technology, natural sciences and other subjects. Since all of these students are in the beginning of their programs, these differences probably reflect sample-selection effects, rather than influences from the education.

\section{Implications for optimal taxation}

Both commodity and income taxation are typically seen as distortionary (e.g. Atkinson and Stiglitz, 1980). However, as argued by Frank (1985a), in a situation where people care about relative consumption, implying positional externalities, there are pure efficiency arguments in favor of differential commodity taxation, rather than lump-sum taxes. In this section we derive optimal tax expressions as functions of the marginal degree of positionality for different goods. We then use our empirical results to calculate Pareto efficient tax levels for the goods considered.

Assume that there are $n$ individuals consuming $g$ goods. The utility function for an arbitrary individual $K$ with positional concerns can be written as:

$$
U^{K}=v^{K}\left(x^{K}, r^{K}\right)=u^{K}\left(x^{K}, \bar{x}\right)
$$


where $x^{K}=\left(x_{1}^{K}, x_{2}^{K}, \ldots, x_{g}^{K}\right), r^{K}=\left(r_{1}^{K}, r_{2}^{K}, \ldots, r_{g}^{K}\right)$ and $\bar{x}=\left(\bar{x}_{1}, \bar{x}_{2}, \ldots \bar{x}_{g}\right)$ are vectors of absolute consumption, relative consumption and mean (absolute) consumption for individual $K$. We assume that $v$ is quasi-concave in all elements of $x$ and $r$. Under an additive formulation we have that $r^{K} \equiv x^{K}-\bar{x}$ so that $U^{K}=v^{K}\left(x^{K}, x^{K}-\bar{x}\right)$, and under a ratio formulation we have that $r^{K}=x^{K} / \bar{x}$, implying that $U^{K}=v^{K}\left(x^{K}, x^{K} / \bar{x}\right)$.

A Pareto efficient allocation can be found by maximizing utility for individual $K$ while holding utility constant for everybody else, and given the budget constraint with prices normalized to one. This implies the following Lagrangean:

$$
u^{K}\left(x^{K}, \bar{x}\right)-\sum_{i_{-K}} \lambda_{i}\left(U_{0}^{i}-u^{i}\left(x^{i}, \bar{x}\right)\right)+\mu\left(Y-\sum_{i} x^{i}\right) .
$$

The first order conditions for an arbitrary individual $L$ and goods $x_{j}$ and $x_{0}$ can be combined to:

$$
\frac{\partial u^{L}}{\partial x_{j}^{L}} / \frac{\partial u^{L}}{\partial x_{0}^{L}}=\frac{1+\frac{1}{n} \sum_{i} \frac{\partial u^{i} / \partial \bar{x}_{0}}{\partial u^{i} / \partial x_{0}^{i}}}{1+\frac{1}{n} \sum_{i} \frac{\partial u^{i} / \partial \bar{x}_{j}}{\partial u^{i} / \partial x_{j}^{i}}}
$$

The marginal rate of substitution (MRS) between the goods should hence not equal the marginal rate of transformation (MRT), but rather an expression that is corrected for the negative externalities arising from the importance of relative consumption. Given the standard competitiveness assumption that an individual takes average consumption and prices as given, individual utility maximization implies that:

$$
\frac{\partial u^{L} / \partial x_{J}^{L}}{\partial u^{L} / \partial x_{0}^{L}}=1+t_{j}
$$

Optimality can be achieved with a tax on good $j$ taking good 0 to be an untaxed numeraire, which is natural to interpret as leisure. Combining (8) and (9) gives 


$$
t_{j}=\frac{1}{n} \sum_{i} \frac{\partial u^{i} / \partial \bar{x}_{0}}{\partial u^{i} / \partial x_{0}^{i}}-\frac{1}{n} \sum_{i} \frac{\partial u^{i} / \partial \bar{x}_{j}}{\partial u^{i} / \partial x_{0}^{i}} \equiv M E C_{j}-M E C_{0} .
$$

The optimal tax is simply equal to the difference in marginal external cost, MEC, between good $j$ and leisure (the untaxed numeraire good) in terms of summed marginal willingness to pay. In the case where leisure is purely non-positional, (10) reduces to a standard Pigouvian externality-correcting tax.

Using (6) we can explicitly use the marginal degree of positionality to get some more insight on the optimal tax. For the additive-comparison case we have that

$$
\frac{\partial u^{i} / \partial \bar{x}_{j}}{\partial u^{i} / \partial x_{j}^{i}}=-\frac{\partial v^{i} / \partial r_{j}^{i}}{\partial v^{i} / \partial x_{j}^{i}+\partial v^{i} / \partial r_{j}^{i}}=-\alpha_{j}^{i},
$$

where $\alpha_{j}^{i}$ is the marginal degree of positionality as defined in equation (3), implying that (10) can be re-written as

$$
t_{j}=\frac{\bar{\alpha}_{j}-\bar{\alpha}_{0}}{1-\bar{\alpha}_{j}}
$$

which is increasing in the positionality for $\operatorname{good} j$, as expected. Hence, in the additive comparison case the optimal tax can be expressed as a simple expression of the mean degrees of positionality.

In the ratio-comparison case we have that:

$$
\frac{\partial u^{i} / \partial \bar{x}_{j}}{\partial u^{i} / \partial x_{j}^{i}}=-\frac{x_{j}^{i}}{\bar{x}_{j}} \frac{\partial v^{i} / \partial r_{j}^{i} 1 / \bar{x}_{j}}{\partial v^{i} / \partial x_{j}^{i}+\partial v^{i} / \partial r_{j}^{i} 1 / \bar{x}_{j}}=-\frac{x_{j}^{i}}{\bar{x}_{j}} \alpha_{j}^{i} .
$$

In this case, (10) can thus be re-written as 


$$
t_{j}=\frac{\frac{1}{n} \sum_{i} \frac{x_{j}^{i}}{\bar{x}_{j}} \alpha_{j}^{i}-\frac{1}{n} \sum_{i} \frac{x_{0}^{i}}{\bar{x}_{0}} \alpha_{0}^{i}}{1-\frac{1}{n} \sum_{i} \frac{x_{j}^{i}}{\bar{x}_{j}} \alpha_{j}^{i}}=\frac{\bar{\alpha}_{j}\left[1+\operatorname{cov}\left(\frac{\alpha_{j}}{\bar{\alpha}_{j}}, \frac{x_{j}}{\bar{x}_{j}}\right)\right]-\bar{\alpha}_{0}\left[1+\operatorname{cov}\left(\frac{\alpha_{0}}{\bar{\alpha}_{0}}, \frac{x_{0}}{\bar{x}_{0}}\right)\right]}{1-\bar{\alpha}_{j}\left[1+\operatorname{cov}\left(\frac{\alpha_{j}}{\bar{\alpha}_{j}}, \frac{x_{j}}{\bar{x}_{j}}\right)\right]} .
$$

Hence, in the ratio-comparison case the optimal tax does not only depend on the mean degrees of positionality, but also on the normalized covariances between positionality and consumption of the good. The intuitive reason is that individuals' marginal willingness to pay for a reduction in average consumption of the good increases with their own consumption of the good; contrary to the additive comparison case, where the marginal willingness to pay is independent of their own consumption. The tax expression reduces to the same as that of the additive comparison case if the covariance terms are zero. To provide some insight into the magnitude of these terms, consider the following two good Cobb-Douglas utility functions:

$$
\begin{gathered}
u=x r^{\gamma /(1-\gamma)} y=\Rightarrow x^{*}=\frac{M}{2-\gamma} \\
u=x^{1-\gamma} r^{\gamma} y \Rightarrow x^{*}=\frac{M}{2} \\
u=x^{(1-\gamma) / \gamma} r y \Rightarrow x^{*}=\frac{M}{1+\gamma}
\end{gathered}
$$

where $x$ is consumption of a good with a marginal degree of positionality equal to $\gamma$, $r \equiv x / \bar{x}$ is relative consumption of this good, $y$ is consumption of non-positional goods, $M$ is individual income and $x^{*}$ is the utility-maximizing demand of good $x$ in each case when prices are normalized to unity. Assume first that all individuals have preferences according to (15a), but that $\gamma$ varies in the population. ${ }^{9}$ Disregarding income differences, this means that those who are more positional with respect to good $x$ will also consume more of it, since $x^{*}=M /(2-\gamma)$ is increasing in $\gamma$. The direct marginal

\footnotetext{
${ }^{9}$ We have suppressed individual subscripts. Note that we are only interested in the ordinal properties of the utility function. Hence, every monotonic transformation of each separate utility function is equally valid. We can then not say anything from equations $(15 \mathrm{a}-\mathrm{c})$ about cardinal properties such as the marginal utility of income, or about interpersonal utility comparisons.
} 
utility of consuming one more unit of $x$ would then be the same for all with the same consumption irrespective of $\gamma$, since $M R S_{x y \mid r}=y / x$. The marginal status value of $x$ is larger for those with a high $\gamma$, since $M R S_{r y \mid x}=\frac{\gamma}{1-\gamma} \frac{y}{r}$ (which increases in $\gamma$ for a given consumption bundle). This case implies a positive covariance expression. One can for example consider fashion clothes, where the direct utility may be about the same for most people.

Now consider (15c) instead. Here we have that those who are more positional with respect to good $x$ will consume less of it, since $x^{*}=M /(1+\gamma)$ is decreasing in $\gamma$. In this case, those with a high $\gamma$ would have a lower direct marginal utility of consuming $x$ compared to other goods, since $M R S_{x y \mid r}=\frac{1-\gamma}{\gamma} \frac{y}{x}$. The marginal status value of $x$ would be the same irrespective of $\gamma$, since $M R S_{r y \mid x}=\frac{y}{r}$. This case implies a negative covariance expression. Possible examples include heavy trucks, where those who buy them on average probably do so due to high "use-values" and not because they derive more status than others from buying them. This case illustrates that a high positionality factor for a certain good may not be due to high status values, but rather to low direct use values. Equation (15b) presents an intermediate case, where consumption of $x$ is independent of $\gamma$. In this case, a high $\gamma$ reflects a combination of low use values and high status values, and the covariance expression is zero here. On average, it appears reasonable that private cars could belong to this group. Some may buy new cars due to high use values, implying a low $\gamma$ (for an average status concern), while others buy them largely for the status effect.

Let us now use the results from the experiments for calculating the optimal taxes. In all cases we assume that vacation is untaxed (and it is often assumed to be untaxable too). Table 7 reports the optimal taxes for both utility functions. For the ratiocomparison case we assume, in the absence of any other information, that the normalized covariances are all zero. In this case the optimal tax expressions are the same for the additive and the ratio comparison cases, but the estimated mean positionality degrees are different. 
>> Table 7.

The results show that relatively positional goods such as cars and housing should, based on pure efficiency considerations, have a corrective tax equal to approximately $30 \%$ of the production price, or around 50\% if we exclude the lexicographic responses, while there is no need to tax relatively non-positional goods such as insurance. The tax levels obtained for housing and cars are non-negligible, without being extreme. Introducing a set of differential consumption taxes would thus imply a Pareto improvement compared to relying solely on individual-specific lump-sum taxation. This result is based on the standard externality argument, i.e. increasing consumption for one individual implies decreased relative consumption for others.

The result would of course be more complicated in a more realistic second-best world with no possibilities of using differential lump-sum taxation. Still, the first-best optimal externality-correcting taxation has been shown to often provide a good approximation to the second-best taxation (cnf. Sandmo, 1975; Bovenberg and de Mooij, 1994; Kaplow, 1996). In addition to correcting for positional externalities among public goods, there are also arguments raised for increased redistribution due to relativeincome effects. Boskin and Sheshinski (1978) and Ireland (2001) find for optimal linear and non-linear income taxes, respectively, that the marginal tax rates are typically higher in the presence of relative income effects. The basic intuition is straightforward: When utility depends on relative income, but not on relative leisure, the negative efficiency effect of an increased income tax is partly off-set by a positive externality effect. Since the optimal tax in itself is a tradeoff between efficiency and equity effects, this tradeoff will now imply more equity, which is obtained by higher taxes. In our case, we have found that leisure is also positional, but to a lesser degree compared to income. Consequently, the distributional argument by Boskin and Sheshinski and Ireland is still valid, although to a smaller extent due to the positionality in leisure. Nevertheless, more research is clearly needed both in relation to optimal taxation in a second-best world, and on measuring positionality per se. 


\section{Conclusions}

We have found that, on average, both relative and absolute income, as well as consumption, matter for individual utility, or well-being. The differences are in the expected direction, so that goods widely considered to be positional, like houses and car ownership, are also found to be more positional than goods typically seen as nonpositional, such as vacation and insurance. Income is in between, which is also expected. In addition, however, we found the mean estimates of the marginal degree of positionality for houses and car ownership to be much smaller than unity, implying that absolute consumption is still important. At the same time, the mean degree of positionality is considerable for vacation and insurance, implying that relative consumption is important here too, contrary to what is typically assumed in the literature. We do not consider this finding per se unintuitive. Indeed, would you be equally content with a three week vacation if others have five weeks, as if they were to have only one week? And wouldn't you feel less secure for the same insurance level if you knew that most others are better insured than you?

However, the results from experimental and survey-based studies, including this one, should always be treated with care. One reason that goods such as cars are expected to be more positional than insurance is that cars are more visible. In the experimental context, all goods are in a sense equally visible for the respondents when they make their choices. This may imply that vacation and insurance are less positional in reality than what the results here indicate. Still, as far as we know this is the first attempt to explicitly estimate the positionality degree for different goods, and we therefore strongly welcome other empirical strategies, experimental set-ups, and samples to increase the knowledge in this important area, and also to see how robust the findings in this paper are.

Based on our empirical results, we derived and computed Pareto efficient tax levels in a first-best economy. The more positional goods, houses and cars, should then have a corrective tax of $28-67 \%$ based on the production price, depending on assumptions. Needless to say, there are many practical problems associated with detailed differential commodity taxation, as discussed e.g. by Frank (1999) and Ireland (2001). Even so, it is important to know where to begin simplifying when designing tax systems or economic policy in general. 


\section{Appendix 1: Proof of the relationship between relative income and relative consumption}

Let us consider the consumer choice with $n$ different goods, which are positional to a varying degree. It is convenient to write the utility functions as follows:

$$
U=v\left(x_{1}, \ldots, x_{n}, r_{1}, \ldots, r_{n}\right)=u\left(x_{1}, \ldots, x_{n} \bar{x}_{1}, \ldots, \bar{x}_{n}\right)
$$

where $v$ is quasi-concave in its arguments. Since we are not interested in price changes, we can normalize the consumer price for all goods to unity. It is also useful to express some (quasi-) indirect utility functions as follows:

$$
U=\omega\left(m, r_{m}, a_{1}, \ldots, a_{n}\right) \equiv \omega\left(m, r_{m}, \frac{\bar{x}_{1}}{\bar{m}}, \ldots, \frac{\bar{x}_{n}}{\bar{m}}\right)=V\left(m, r_{1}, \ldots, r_{n}\right)
$$

where $m$ is the income needed to obtain utility $U$ at the relative consumption levels $r_{1}, \ldots, r_{n}$, or at fixed relative income $r_{m}$ and market shares for different goods $a_{1}, \ldots, a_{n}$. Differentiating (A2) with respect to $m$, and using (3) for each good $j$, we get:

$$
\frac{\partial \omega}{\partial m}+\frac{\partial \omega}{\partial r_{m}} \frac{\partial r_{m}}{\partial m}=\frac{\partial V}{\partial m}+\sum_{j} \frac{\partial V}{\partial r_{j}} \frac{\partial r_{j}}{\partial x_{j}} \frac{\partial x_{j}}{\partial m}=\frac{\partial V}{\partial m}+\sum_{j} \alpha_{j} \frac{\partial u}{\partial x_{j}} \frac{\partial x_{j}}{\partial m}=\frac{\partial V}{\partial m}+\rho \sum_{j} \alpha_{j} \frac{\partial x_{j}}{\partial m}
$$

We have directly that $\frac{\partial \omega}{\partial m}=\frac{\partial V}{\partial m}$. From individual utility maximization, taking consumption of others as given and price normalized to 1 , we have that $\rho=\frac{\partial u}{\partial x_{j}}=\frac{\partial v}{\partial x_{j}}+\frac{\partial v}{\partial r_{j}} \frac{\partial r_{j}}{\partial x_{j}}=\frac{\partial \omega}{\partial m}+\frac{\partial \omega}{\partial r_{m}} \frac{\partial r_{m}}{\partial m}$ at the optimum. Hence, we can re-write (A3) as:

$$
\frac{\frac{\partial \omega}{\partial r_{m}} \frac{\partial r_{m}}{\partial m}}{\frac{\partial \omega}{\partial m}+\frac{\partial \omega}{\partial r_{m}} \frac{\partial r_{m}}{\partial m}}=\sum_{j} \alpha_{j} \frac{\partial x_{j}}{\partial m}
$$


The left-hand side of (A4) is a measure of the marginal degree of positionality for income, given that the overall market shares of different goods are held constant. Thus we have:

$$
\alpha_{m}=\sum_{j} \alpha_{j} \frac{\partial x_{j}}{\partial m}=\sum_{j} \sigma_{j} \gamma_{j} \alpha_{j}
$$

where $\sigma_{j} \equiv \frac{\partial x_{j}}{\partial m} \frac{m}{x_{j}}$ is the income elasticity for $\operatorname{good} j$, and $\gamma_{j} \equiv \frac{x_{j}}{m}$ is the individual expenditure share for good $j$. 


\section{Appendix 2 Sample questions}

\section{$\underline{\text { Income experiment }}$}

Question 2. Choose between society A and B for your grandchild.

Society A: Your grandchild's income is 300.000 Colones/month The average income in society $\mathrm{A}$ is 360.000 Colones/month

Society B: Your grandchild's income is 288.000 Colones/month The average income in society B is 240.000 Colones/month

Given the prerequisites described in the introduction, choose the society you consider to be in the best interest of your grandchild, i.e. the society in which your grandchild will be most content.

\section{$\square$ Society A \\ $\square$ Society B}

(It is important that you focus only on the best interest of your grandchild, not on the society that is best for others or on the better society overall. Also, remember that prices are the same in both societies.)

\section{Consumption experiment}

The societies A and B are the same except for the information given below. Hence, even though other people spend more (on average) on cars in society A, their consumption of other goods is the same in society A and B.

Question 2. Choose between society A and B for your grandchild.

Society A - The company provides a car with a market value of 4,500,000 Colones for your grandchild.

- In the society the average market value of cars is 5,400,000 Colones.

Society B - The company provides a car with a market value of 3,675,000 Colones for your grandchild.

- In the society the average market value of cars is 3,600,000 Colones.

Choose the society you consider to be in the best interest of your grandchild, i.e. the society in which your grandchild will be most content. 


\section{References}

Akerlof, G.A. (1997). “Social Distance and Social Decisions”. Econometrica 65, 1005 1027.

Akerlof, G.A. and R.E. Kranton (2000). "Economics and Identity”. Quarterly Journal of Economics 115: 715-753.

Atkinsson, A.B. and J.E. Stiglitz (1980). Lecture in Public Economics. Singapore: McGraw Hill.

Boskin, M.J. and E. Sheshinski (1978). "Individual Welfare Depends upon Relative Income". Quarterly Journal of Economics. 92, 589-601.

Bovenberg, A. L. and R. A. de Mooij (1994). "Environmental Levies and Distortionary Taxation." American Economic Review 94, 1085-89.

Brekke, K.-A. (1997). Economic Growth and the Environment. Cheltenham: Edward Elgar.

Brekke, K.-A. and R.B. Howarth (2001). Affluence, Well-Being and Environmental Quality. Cheltenham, Edward Elgar.

Carroll, C. J. Overland and D. Weil (1997). "Comparison Utility in a Growth Model". Journal of Economic Growth 2, 339-367.

Clark, A.E. and A.J. Oswald (1998). "Comparison-Concave Utility and Following Behaviour in Social and Economic Settings". Journal of Public Economics 70, 133155 .

Corneo, G. and O. Jeanne (1997). "Conspicuous Consumption, Snobbism and Conformism”. Journal of Public Economics 66, 55-71.

Duesenberry, J.S. (1949). Income, Savings, and the Theory of Consumer Behaviour, Cambridge: Harvard University Press.

Easterlin, R.A. (1974). "Does Economic Growth Enhance the Human Lot? Some Empirical Evidence", in P.A. David and M. Reder (eds.) Nations and Households in Economic Growth: Essays in Honour of Moses Abramovitz. Palo Alto: Stanford University Press: 89-125.

Easterlin, R.A. (1995). "Will Raising the Incomes of All Increase the Happiness of All?". Journal of Economic Behavior and Organization 27, 35-47.

Frank, R.H (1985a). Choosing the Right Pond: Human Behavior and the Quest for Status. New York: Oxford University Press. 
Frank, R.H. (1985b). "The Demand for Unobservable and Other Nonpositional Goods". American Economic Review 75, 101-16.

Frank, R. H. (1999). Luxury Fever. New York: Free Press.

Frank, R.H. and R.M. Hutchens (1993) "Wages, seniority, and the Demand for Rising Consumption Profiles". Journal of Economic Behavior and Organization 21, 251-76.

Greene, W. (2000). Econometric Analysis. New Jersey: Prentice-Hall.

Hirsch, F. (1976). Social Limits to Growth. Cambridge: Harvard University Press.

Holländer, H. (2001). “On the Validity of Utility Statements: Standard Theory Versus Duesenberry's". Journal of Economic Behavior and Organization 45, 227-249.

Ireland, N.J. (2001). “Optimal Income Tax in the Presence of Status Effects”. Journal of Public Economics 81, 193-212.

Johansson-Stenman, O., F. Carlsson and D. Daruvala (2002). "Measuring Hypothetical Grandparents Preferences for Equality and Relative Standings". Economic Journal, forthcoming.

Kaplow, L. (1996). "The Optimal Supply of Public Goods and the Distortionary Cost of Taxation”. National Tax Journal 49, 513-33.

Knell, M. (1999). "Social Comparisons, Inequality, and Growth". Journal of Institutional and Theoretical Economics 155, 664-695.

Layard, R. (1980). "Human Satisfaction and Public Policy”. Economic Journal, vol. 90, 737-750.

Lungqvist and Uhlig (2000). "Tax Policy and Aggregate Demand Management Under Catching Up with the Joneses". American Economic Review 90, 356-366.

Mandeville, B. (1723). The Fable of the Bees; or, Private Vices, Public Benefits. London: J Tonson.

Marx, K. (1891). Wage Labour and Capital, the first English translation of the pamphlet, first published (in German) in Neue Rheinische Zeitung, Nos. 264-267 and 269, April 5-8 and 11, 1849.

Ng, Y.-K. (1987). "Relative Income Effects and the Appropriate Level of Public Expenditure", Oxford Economic Papers 39, 293-300.

Ng, Y.-K. and J. Wang (1993). "Relative Income, Aspiration, Environmental Quality, Individual and Political Myopia - Why May the Rat-Race for Meeting Growth be Welfare-Reducing?”. Mathematical Social Sciences 26, 3-23. 
Osmani, A.J. (1998). "Happiness and Economic Performance”. In (M. Nussbaum and A. Sen, eds) The Quality of Life. Oxford: Oxford University Press.

Oswald, A.J. (1998). "Happiness and Economic Performance”. Economic Journal 107, 1815-1831.

Payne, J., J. Bettman and E. Johnson (1993). The Adaptive Decisionmaker. Cambridge: Cambridge University Press.

Persson, M. (1995), "Why are Taxes so High in Egalitarian Societies?" Scandinavian Journal of Economics 97, 469-76.

Sandmo, A. (1975). "Optimal Taxation in the Presence of Externalities." Swedish Journal of Economics. 77, 86-98.

Solnick, S. and D. Hemenway (1998). "Is More Always Better?: A Survey on Positional Concerns". Journal of Economic Behavior \& Organization 37, 373-83.

Veblen, T. (1899). The Theory of the Leisure Class, New York: MacMillan.

Weiss, Y. and C. Fershtman (1998). "Social Status and Economic Performance: A Survey". European Economic Review 42, 801-820. 
Table 1. Societies in relative-income experiment, amount of Colones per month.

\begin{tabular}{|l|l|r|r|r|r|}
\hline Set & & \multicolumn{1}{|l|}{$\begin{array}{l}\text { Grandchild's } \\
\text { income }\end{array}$} & $\begin{array}{l}\text { Average } \\
\text { income }\end{array}$ & \multicolumn{2}{l}{$\begin{array}{l}\text { Marginal degree of positionality if indifference } \\
\text { between A and B }\end{array}$} \\
\hline & & & Ratio comparison, $\gamma$ & Additive comparison, $\delta$ \\
\hline & Society A & 300,000 & 360,000 & 0 & 0 \\
\hline 1 & Society B & 300,000 & 240,000 & 0.125 & 0.25 \\
\hline 2 & Society B & 285,000 & 240,000 & 0.5 & 0.25 \\
\hline 3 & Society B & 270,000 & 240,000 & 0.75 & 0.45 \\
\hline 4 & Society B & 245,000 & 240,000 & 0.9 & 0.67 \\
\hline 5 & Society B & 220,000 & 240,000 & 1.0 & 0.75 \\
\hline 6 & Society B & 210,000 & 240,000 & & 0.83 \\
\hline 7 & Society B & 200,000 & 240,000 & & \\
\hline
\end{tabular}

Table 2. Societies in relative-consumption experiment. Amounts in Colones per month, except for vacation, which is in days per year.

\begin{tabular}{|c|c|c|c|c|c|}
\hline \multirow[t]{2}{*}{ Set } & & \multirow[t]{2}{*}{$\begin{array}{l}\text { Grandchild's } \\
\text { consumption }\end{array}$} & \multirow[t]{2}{*}{$\begin{array}{l}\text { Average } \\
\text { consumption }\end{array}$} & \multicolumn{2}{|c|}{$\begin{array}{l}\text { Marginal degree of positionality if indifference } \\
\text { between society } A \text { and } B\end{array}$} \\
\hline & & & & Ratio comparison, $\gamma$ & Addit. comparison, $\delta$ \\
\hline & Car A & $4,500,000$ & $5,400,000$ & & \\
\hline 1 & Car B & $4,065,000$ & $3,600,000$ & 0.25 & 0.24 \\
\hline 2 & Car B & $3,670,000$ & $3,600,000$ & 0.5 & 0.46 \\
\hline 3 & Car B & $3,320,000$ & $3,600,000$ & 0.75 & 0.66 \\
\hline & Housing A & $36,000,000$ & $43,200,000$ & & \\
\hline 1 & Housing B & $32,500,000$ & $28,000,000$ & 0.25 & 0.24 \\
\hline 2 & Housing B & $29,400,000$ & $28,000,000$ & 0.5 & 0.46 \\
\hline 3 & Housing B & $26,500,000$ & $28,000,000$ & 0.75 & 0.66 \\
\hline & Insurance A & 900,000 & $1,080,000$ & & \\
\hline 1 & Insurance B & 813,000 & 720,000 & 0.25 & 0.24 \\
\hline 2 & Insurance B & 735,000 & 720,000 & 0.5 & 0.46 \\
\hline 3 & Insurance B & 663,000 & 720,000 & 0.75 & 0.66 \\
\hline & Vacation A & 20 & 25 & & \\
\hline 1 & Vacation B & 18 & 16 & 0.25 & 0.24 \\
\hline 2 & Vacation B & 16 & 16 & 0.5 & 0.46 \\
\hline 3 & Vacation B & 14 & 16 & 0.75 & 0.66 \\
\hline
\end{tabular}


Table 3. Results relative income experiment

\begin{tabular}{|l|l|r|r|r|}
\hline \multicolumn{2}{|c|}{ Parameter values } & No. & Freq. & Cum. Freq. \\
\hline Ratio comparison & Additive comparison & & & \\
\hline$\gamma<0$ & $\delta<0$ & 62 & 0.22 & 0.22 \\
\hline $0<\gamma<0.125$ & $0<\delta<0.125$ & 12 & 0.22 & 0.44 \\
\hline $0.125<\gamma<0.25$ & $0.125<\delta<0.25$ & 27 & 0.04 & 0.48 \\
\hline $0.25<\gamma<0.5$ & $0.25<\delta<0.45$ & 23 & 0.10 & 0.58 \\
\hline $0.5<\gamma<0.75$ & $0.45<\delta<0.67$ & 3 & 0.08 & 0.66 \\
\hline $0.75<\gamma<0.9$ & $0.67<\delta<0.75$ & 8 & 0.01 & 0.67 \\
\hline $0.9<\gamma<1$ & $0.75<\delta<0.83$ & 87 & 0.02 & 0.69 \\
\hline$\gamma \geq 1$ & $\delta>0.83$ & & 0.31 & 1.00 \\
\hline
\end{tabular}

Table 4. Results of consumption experiments

\begin{tabular}{|l|r|r|r|r|r|r|r|r|r|r|r|r|}
\hline & \multicolumn{3}{|c|}{ Car } & \multicolumn{3}{|c|}{ Housing } & \multicolumn{3}{|c|}{ Insurance } & \multicolumn{3}{c|}{ Vacation } \\
\hline & No. & Freq. & $\begin{array}{l}\text { Cum } \\
\text { freq. }\end{array}$ & No. & Freq. & $\begin{array}{l}\text { Cum } \\
\text { freq. }\end{array}$ & No. & Freq. & $\begin{array}{l}\text { Cum } \\
\text { freq. }\end{array}$ & No. & Freq. & $\begin{array}{l}\text { Cum } \\
\text { freq. }\end{array}$ \\
\hline $\begin{array}{l}\gamma<0.25 \\
\delta<0.24\end{array}$ & 96 & 0.32 & 0.32 & 100 & 0.33 & 0.33 & 158 & 0.51 & 0.51 & 157 & 0.51 & 0.51 \\
\hline $\begin{array}{l}0.25<\gamma<0.5 \\
0.24<\delta<0.46\end{array}$ & 40 & 0.13 & 0.45 & 24 & 0.08 & 0.41 & 27 & 0.09 & 0.60 & 26 & 0.09 & 0.60 \\
\hline $\begin{array}{l}0.5<\gamma<0.75 \\
0.46<\delta<0.66\end{array}$ & 35 & 0.12 & 0.57 & 37 & 0.12 & 0.53 & 31 & 0.10 & 0.70 & 28 & 0.09 & 0.69 \\
\hline $\begin{array}{l}\gamma>0.75 \\
\delta>0.66\end{array}$ & 130 & 0.43 & 1.00 & 141 & 0.47 & 1.00 & 96 & 0.30 & 1.00 & 96 & 0.31 & 1.00 \\
\hline \begin{tabular}{l} 
Mean values \\
\hline
\end{tabular}$=0.55, \bar{\delta}=0.50$ & $\bar{\gamma}=0.56, \bar{\delta}=0.51$ & $\bar{\gamma}=0.41, \bar{\delta}=0.37$ & $\bar{\gamma}=0.41, \bar{\delta}=0.36$ \\
\hline
\end{tabular}


Table 5. Impact of removing lexicographic responses on the mean marginal degree of positionality.

\begin{tabular}{|c|c|c|c|}
\hline & $\begin{array}{l}\text { Removing always non- } \\
\text { positional }\end{array}$ & $\begin{array}{l}\text { Removing always } \\
\text { highly positional }\end{array}$ & Removing both types \\
\hline Car & 0.68 & 0.47 & 0.60 \\
\hline Housing & 0.70 & 0.49 & 0.63 \\
\hline Insurance & 0.50 & 0.31 & 0.38 \\
\hline Vacation & 0.50 & 0.30 & 0.38 \\
\hline
\end{tabular}

Table 6. Ordered probit marginal effects at sample means for the income and consumption experiments.

\begin{tabular}{|c|c|c|c|c|}
\hline $\begin{array}{l}\text { Variable } \\
\text { [Mean] }\end{array}$ & $\gamma<0.25$ & $0.25<\gamma<0.5$ & $0.5<\gamma<0.75$ & $\gamma>0.75$ \\
\hline & \multicolumn{4}{|c|}{ Income } \\
\hline Female $[0.478]$ & $-0.1636^{* * *}$ & 0.0017 & 0.0097 & $0.1522^{* * *}$ \\
\hline Parents' Income [4.111] & $0.0233^{* *}$ & -0.0003 & -0.0014 & $-0.0216^{* *}$ \\
\hline Left [0.399] & $-0.1072^{* * *}$ & 0.0007 & 0.0060 & $0.1005^{* *}$ \\
\hline Economics [0.097] & $-0.1628^{* * *}$ & $-0.0050^{* * *}$ & 0.0044 & $0.1634^{* * *}$ \\
\hline Law $[0.201]$ & $-0.1877^{* * *}$ & $-0.0045^{* * *}$ & 0.0060 & $0.1862^{* * *}$ \\
\hline \multirow[t]{2}{*}{ Social Science [0.302] } & $-0.1115^{* * *}$ & -0.0001 & 0.0058 & $0.1060^{* *}$ \\
\hline & \multicolumn{4}{|c|}{ Car } \\
\hline Female [0.479] & $-0.0556^{*}$ & $-0.0065^{* *}$ & 0.0000 & 0.0621 \\
\hline Parents' Income [4.020] & 0.0052 & 0.0006 & 0.000 & -0.0058 \\
\hline Left [0.392] & -0.0025 & -0.0003 & 0.000 & 0.0028 \\
\hline Economics [0.104] & $-0.0893^{* * *}$ & $-0.0140^{* * *}$ & -0.0032 & $0.1065^{*}$ \\
\hline Law [0.208] & $-0.1105^{* * *}$ & $-0.0169^{* * *}$ & -0.0036 & $0.1309^{* *}$ \\
\hline \multirow[t]{2}{*}{ Social Science [0.285] } & $-0.1057^{* * *}$ & $-0.0149^{* * *}$ & -0.023 & $0.1230^{* *}$ \\
\hline & \multicolumn{4}{|c|}{ House } \\
\hline Female [0.493] & $-0.1089^{* * *}$ & $-0.0079^{* *}$ & -0.0037 & $0.1206^{* *}$ \\
\hline Parents' Income [4.035] & 0.0135 & 0.0010 & 0.0005 & -0.0149 \\
\hline Left [0.396] & $-0.0711^{*}$ & $-0.0055^{*}$ & $-0.0029^{* * *}$ & 0.0795 \\
\hline Economics [0.101] & 00013 & 0.0001 & 0.0000 & -0.0015 \\
\hline Law $[0.215]$ & $-0.0936^{*}$ & $-0.0083^{*}$ & $-0.0057^{* * *}$ & $0.1076^{*}$ \\
\hline \multirow[t]{2}{*}{ Social Science [0.292] } & $-0.0211^{*}$ & -0.0016 & -0.0008 & 0.235 \\
\hline & \multicolumn{4}{|c|}{ Insurance } \\
\hline Female [0.492] & $-0.0995^{* * *}$ & 0.0020 & 0.0088 & $0.0887^{* *}$ \\
\hline Parents' Income [4.043] & 0.0167 & -0.0003 & -0.0015 & $-0.0148^{*}$ \\
\hline Left $[0.371]$ & 0.0126 & -0.0003 & -0.0011 & -0.0112 \\
\hline Economics [0.097] & $-0.1423^{* * *}$ & -0.0016 & 0.0076 & $0.1363^{* * *}$ \\
\hline Law [0.204] & $-0.1322^{* * *}$ & -0.0001 & 0.0086 & $0.1237^{\text {*** }}$ \\
\hline \multirow[t]{2}{*}{ Social Science [0298] } & $-0.1571^{* * *}$ & 0.0005 & 0.0109 & $0.1457^{* * *}$ \\
\hline & \multicolumn{4}{|c|}{ Vacation } \\
\hline Female [0.493] & $-0.1623^{* * *}$ & 0.0047 & 0.0137 & $0.1439^{* * *}$ \\
\hline Parents' Income [4.075] & $0.0198^{*}$ & -0.0006 & -0.0017 & $-0.0175^{* *}$ \\
\hline Left $[0.378]$ & -0.0268 & 0.0008 & 0.0023 & 0.0237 \\
\hline Economics [0.099] & $-0.1735^{* 2 *}$ & -0.0019 & 0.0082 & $0.1673^{* \% *}$ \\
\hline Law [0.207] & $-0.0795^{* * *}$ & 0.0013 & 0.0059 & 0.0723 \\
\hline Social science [0.299] & $-0.1015^{* * *}$ & 0.0019 & 0.0076 & $0.0920^{* *}$ \\
\hline
\end{tabular}

\footnotetext{
significant at a $1 \%$ level, ${ }^{* *}$ significant at a $5 \%$ level, ${ }^{*}$ significant at a $10 \%$ level
} 
Table 7. Optimal taxes correcting for the positional externality with and without lexicographic preferences.

\begin{tabular}{|l|l|l|l|l|}
\hline & \multicolumn{2}{|l|}{ All consistent responses included } & \multicolumn{2}{l|}{ Lexicographic responses excluded } \\
\hline & Ratio comparison & Additive comparison & Ratio comparison & Additive comparison \\
\hline Car & 0.31 & 0.28 & 0.55 & 0.41 \\
\hline Housing & 0.34 & 0.31 & 0.67 & 0.51 \\
\hline Insurance & 0.00 & 0.02 & 0.00 & 0.00 \\
\hline
\end{tabular}

